\title{
Tonsillar Kaposi Sarcoma in an HIV-Negative Patient: A Case Report
}

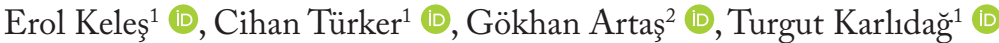 \\ Case Report $>{ }^{1}$ Department of Otorhinolaryngology, Firat University School of Medicine, Elazığ, Turkey \\ ${ }^{2}$ Department of Pathology, Frrat University School of Medicine, Elazığ, Turkey
}

Abstract

ORCID IDs of the authors: E.K. 0000-0003-4443-6714; C.T. 0000-0003-0692-5787; G.A. 0000-0001-5529-4155 T.K. 0000-0003-2748-7309.

Cite this article as: Keles E, Türker C, Artas $G$, Karlıdağ T. Tonsillar Kaposi Sarcoma in an HIV-Negative Patient: A Case Report. Turk Arch Otorhinolaryngol 2019; 57(1): 46-9.

This study was presented at the $13^{\text {th }}$ International Otorhinolaryngology - Head and Neck Surgery, April 5-7, 2018, Ankara, Turkey.

\section{Corresponding Author:}

Cihan Türker; cihan_turker23@hotmail.com

Received Date: 27.04.2018

Accepted Date: 04.09 .2018

Available Online Date: 28.02.2019

๑ Copyright 2019 by Official Journal of the Turkish Society of Otorhinolaryngology and Head and

Neck Surgery Available online at

www.turkarchotolaryngol.net

DOI: 10.5152/ta0.2018.3487
Kaposi's sarcoma $(\mathrm{KS})$ is a rare malignancy associated with AIDS and usually affects skin. The most common causative agent is the Human Herpes Virus Type 8 (HHV-8). In the literature, there are few case reports about $\mathrm{KS}$ with no association to AIDS. In this case report, we report a 72-year-old HIV (-) woman who presented to our clinic with a complaint of fast swelling in the right palatine tonsil and was histopathologically diagnosed as tonsillar KS.

Keywords: Palatine tonsil, Kaposi's sarcoma, human herpes virus, histopathology

\section{Introduction}

Kaposi's sarcoma (KS) was defined by Moritz Kaposi in 1872 (1). A multicentric mucocutaneous neoplasia originating in the endothelium, KS is reported to present in four clinical forms: classic, iatrogenic (post-transplant), endemic, and epidemic. It is a vascular tumor that can involve the skin, mucosa, the respiratory and the gastrointestinal systems (3). In the head and neck region KS is most often seen on the mucosa of the oral cavity, however, cases involving the mucosa of the pharynx, larynx and nasal cavity have also been identified. Oral Kaposi's sarcoma (OKS) is most often seen on the hard and the soft palates, the gingiva, and the dorsum of the tongue (4). Isolated involvement of the tonsils is rarely seen in KS (3).

In this report we present the case of a 72-year-old HIV (-) woman who presented with a fast-growing swelling on the right tonsil and was diagnosed with KS following diagnostic tonsillectomy.

\section{Case Presentation}

The 72-year-old patient presented with a complaint of a growing swelling on her right tonsil that had first appeared three months earlier. The patient reported that she had received antibiotic treatment several times. Examination of the patient showed a non-ulcerated, irregularly-contoured submucosal mass of about $3 \times 4 \mathrm{~cm}$ advancing from the right tonsil toward the hypopharynx (Figure 1). Magnetic resonance imaging (MRI) of the neck revealed a solid mass of 50x $28 \mathrm{~mm}$ with lobulated contours and showing intense contrast involvement that significantly narrowed the oropharyngeal airway at the level of the right tonsil. The mass was seen to have invaded the palatopharyngeus to the right and the constrictor muscle of the pharynx to the left. The mass had advanced toward the right anterior tongue base and generalized lymphadenopathy with a largest mass of 28x15 mm was observed on the right cervical chain (Figure 2).

Right tonsillectomy was performed under general anesthesia. The tonsil material was at $4 \times 3 \times 1 \mathrm{~cm}$ diameter and had an irregular shape with withbrown color. Histopathologic examination revealed reactive follicle structures with distinct germinal centers. Also cleft-like gaps and erythrocyte extravasation was seen. Presence of atypical mitosis was observed. Immunohistochemical examination identified pancytokeratin (-), CD34, CD31, 


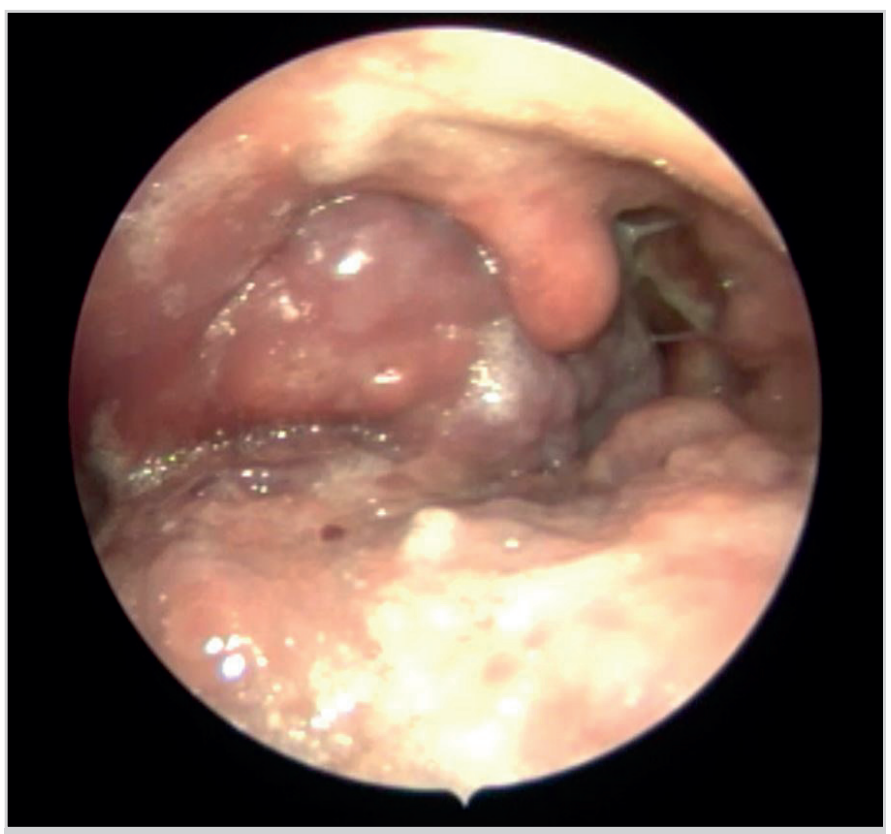

Figure 1. Endoscopic oropharyngeal image of patient

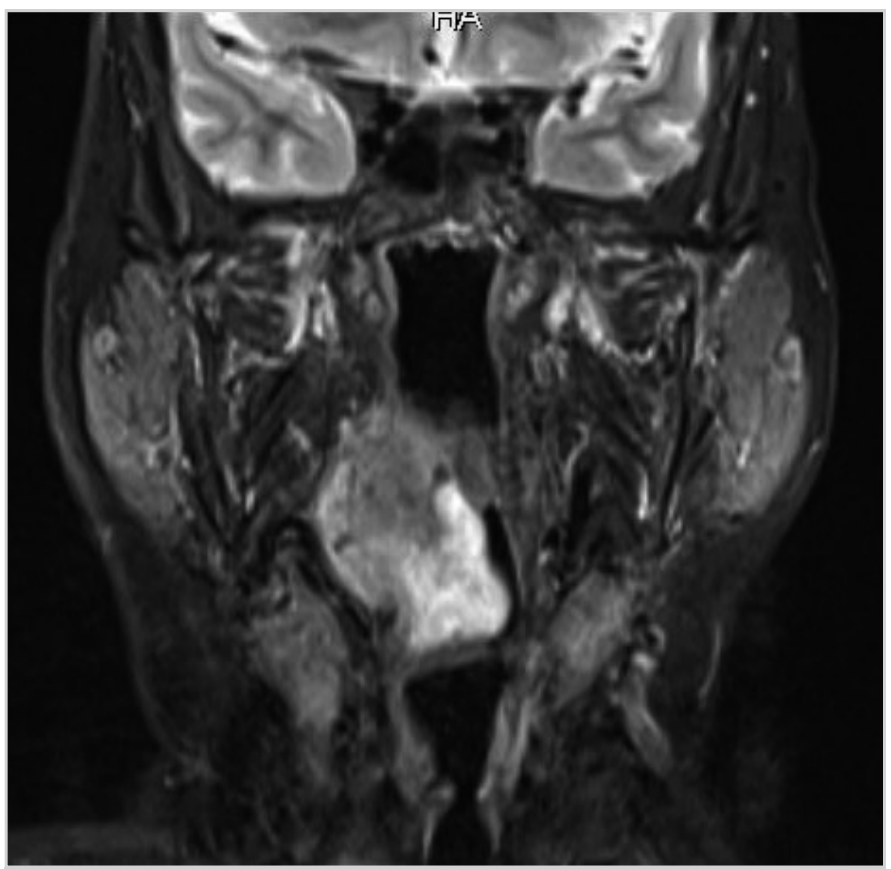

Figure 2. Coronal section MRI of the patient

FLI-1 (+), Human herpes virus 8 (HHV-8) positivity, and Ki67 proliferation index at 20\%. (Figure 3). Histopathologic examination concluded to a Kaposi's sarcoma. Complete blood count, and routine laboratory tests including liver and renal functions did not reveal any pathologies. Her HIV test result was negative. Positron emission tomography/computed tomography examination was performed to investigate the possibility of additional organ or tissue involvements and to identify the stage of the disease. The examination revealed increased malignant metabolic activity in the mass lesion in the right tonsillar region, the right superior jugular and the right subclavicular nodes (Figure 4). The patient was referred to the oncology clinic where she was prescribed a chemotherapeutic agent (paclitaxel, Biolek med-

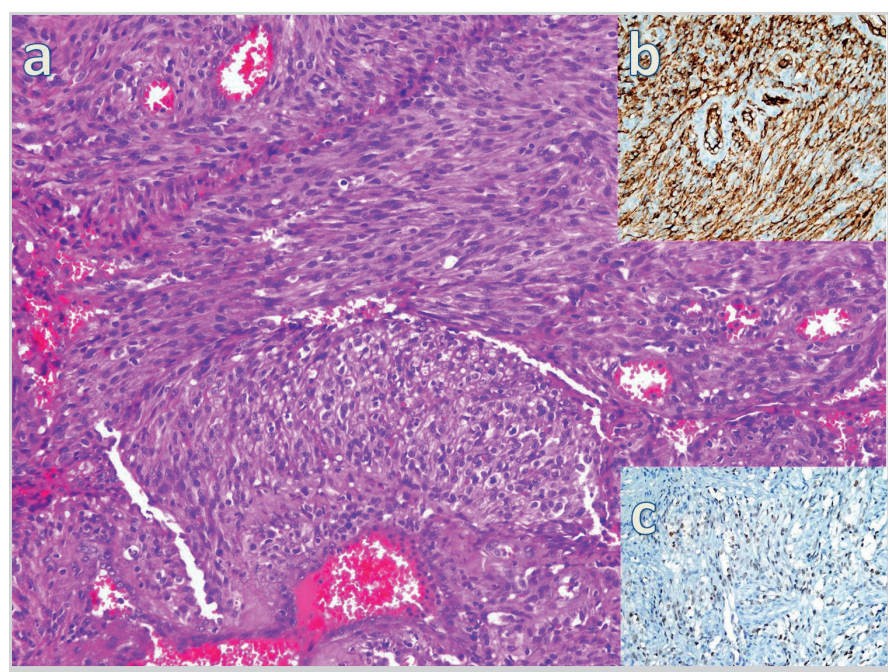

Figure 3. a-c. Lesion consisting of spindle-like endothelial cells (HEX200) (a), CD34 positivity in cells (immunoperoxidase X400) (b), HHV-8 positivity in cells (immunoperoxidase X400)

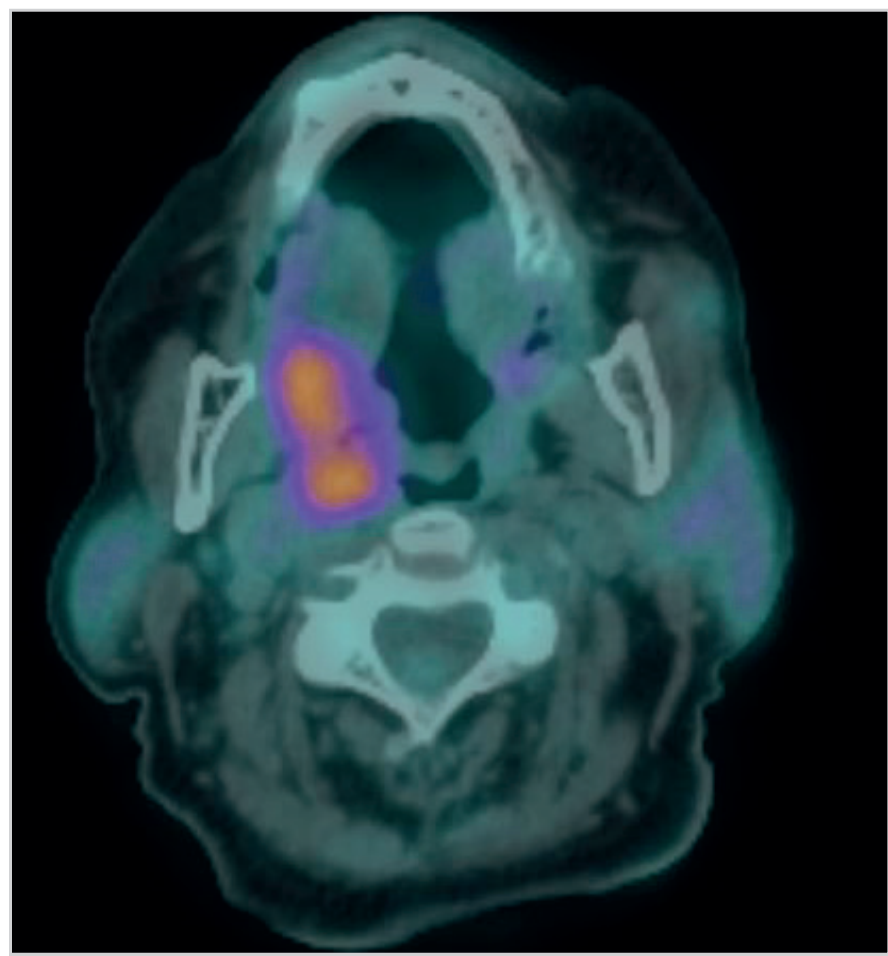

Figure 4. PET-CT axial image of the patient

ical, Ukraine). The patient was regularly followed both by the oncology and otorhinolaryngology clinics, and recurrence was not seen in the first postoperative year. Informed consent was obtained from the patient for this report.

\section{Discussion}

Kaposi's sarcoma is a malignancy that commonly presents together with AIDS. KS incidence in the non-HIV-positive population is $1 / 100,000$, whereas this rate is $1 / 20$ in the HIV-positive population (5).

Oropharyngeal KS, particularly isolated KS of the tonsils is rare with only a few cases reported in the literature. Sikora et 
al. (3) reported two HIV-negative cases in two patients aged 48 and 34 years. The authors reported that the 48-year-old patient presented to their clinic with a growth in the right tonsil, and the 34-year-old patient who was the nephew of the first patient presented with long-term tonsillitis and foul breath. Both of the patients were HIV-negative and neither patients showed recurrence after the three-year follow-up period. Likewise, no recurrence was seen in our patient after the one-year follow-up period. In 2011, Ozbudak et al. (6) reported a 68-year-old HIV-negative male patient who was diagnosed with classic KS of the tonsil after he presented to their clinic with dysphagia and a sore throat. Similar to our case, cutaneous lesions were not observed, and the patient had HHV-8 positivity. Interestingly, the authors reported to have identified microinvasive squamous cell carcinoma together with KS in the lower one-third of the esophagus. The patient was reported to have experienced no undesirable events in the two-and-a-half years following his chemotherapy.

The human herpes virus 8 (HHV-8) is a herpes virus known to be the etiologic agent of all KS sub-forms, including classic, endemic, iatrogenic and AIDS-associated (epidemic) KS (5). This virus is also held responsible for the development of primary effusion lymphoma and multicentric Castleman disease. Serologic methods, polymerase chain reaction or immunohistochemical methods can be used to detect the presence of the HHV-8 (7). In our case, HHV-8 was identified through immunohistochemical examination.

Macroscopically Kaposi's sarcoma presents as irregular macules on the skin in its early stages and develops a papular or nodular appearance in the later stages. Mucosa involvement occurs in the advanced stages of the disease. There are a number of vascular tumors that can clinically or histologically resemble KS lesions (8). Squamous cell carcinoma, lymphoma and bacillary angiomatosis are among the differential diagnoses of KS. While squamous cell carcinomas of the tonsils show unilateral growth and mucosal ulceration, lymphomas demonstrate normal mucosal appearance with asymmetrically growth of the tonsil (9). Bacillary angiomatosis is a bacterial disease characterized by angiomatous skin lesions. KS ranks first among the diseases that can be confused with this disease (10). In our case, bacillary angiomatosis was considered as a differential diagnosis, but eliminated after our patient proved HIV-negative since this disease is associated with HIV.

Kaposi's sarcoma can be treated with radiotherapy, chemotherapy, interferon, or surgery. High activity antiretroviral therapy or a combination of this treatment can be considered in HIV-positive patients. High activity antiretroviral therapy was not considered in our patient since it is a treatment modality used in AIDS-associated KS cases. Chemotherapy may be administered locally (intralesional injections) or systemically (intravenous). Local bleomycin, cisplatin or vinblastine chemotherapy can provide a complete or partial response to cutaneous KS. Various agents such as vincristine, vinblastine, etoposide, bleomycin, docetaxel and paclitaxel can be used in systemic therapy. Paclitaxel has strong antiangiogenic activity that can express its efficacy on KS lesions (12). Medical Oncology department treated the patient with systemic paclitaxel therapy. No recurrence was detected during the one-year regular follow-up visits of the patient.

\section{Conclusion}

Kaposi's sarcoma should be borne in mind as a differential diagnosis in patients who present with a unilateral growth of the tonsil.

Informed Consent: Written informed consent was obtained from the patient who participated in this study.

Peer-review: Externally peer-reviewed.

Author Contributions: Concept - E.K., C.T., G.A., T.K.; Design E.K., C.T., G.A., T.K.; Supervision - E.K., C.T., G.A., T.K.; Resource - E.K., G.A., T.K.; Materials - E.K., C.T., G.A.; Data Collection and/ or Processing - E.K., C.T., G.A., T.K.; Analysis and/or Interpretation - E.K., T.K., G.A.; Literature Search - E.K., C.T., G.A., T.K.; Writing - E.K., C.T., G.A.; Critical Reviews - E.K., G.A., T.K.

Conflict of Interest: The authors have no conflicts of interest to declare.

Financial Disclosure: The authors declared that this study has received no financial support.

\section{References}

1. Reis-Filho JS, Souto-Moura C, Lopes JM. Classic Kaposi's sarcoma of the tongue: case report with emphasis on the differential diagnosis. J Oral Maxillofac Surg 2002 ; 60: 951-4. [CrossRef]

2. Fatahzadeh M, Schwartz RA. Oral Kaposi's sarcoma: A review and update. Int J Dermatol 2013; 52: 666-72. [CrossRef]

3. Sikora AG, Shnayder Y, Yee H, DeLacure MD. Oropharyngeal Kaposi sarcoma in related persons negative for human immunodeficiency virus. Ann Otol Rhinol Laryngol 2008; 117: 172-6. [CrossRef]

4. Patrikidou A, Vahtsevanos K, Charalambidou M, Valeri RM, Xirou P, Antoniades K. Non-AIDS Kaposi's sarcoma in the head and neck area. Head Neck 2009; 31: 260-8. [CrossRef]

5. La Ferla L, Pinzone MR, Nunnari G, Martellotta F, LIeshi A, Tirelli U, et al. Kaposi's sarcoma in HIV-positive patients: The state of art in the HAART-era: Eur Rev Med Pharmacol Sci 2013; 17: 2354-65.

6. Ozbudak IH, Guney K, Mutlu D, Gelen T, Ozbilim G. Bilateral tonsillar and esophageal kaposi sarcoma in an HIV- negative patient: Ear Nose Throat J 2011; 90: E23-6. [CrossRef]

7. Cesarman E, Chang Y, Moore PS, Said JW, Knowles DM. Kaposi's sarcoma-associated herpes virus-like DNA sequences in AIDS-related body-cavity-based lymphomas. N Engl J Med 1995; 332: 1186-91. [CrossRef]

8. Kelly DA, Tuddenham EL. Hemostatic problems in liver disease. Gut 1986; 27: 339-49. [CrossRef]

9. Saul SH, Kapadia SB. Primary lymphoma of Waldeyer's ring. Clinico-pathologic study of 68 cases. Cancer 1985; 56: 157-66.

10. Webster GF, Cockerell CJ, Friedman-Kien AE. The clinical spectrum of bacillary angiomatosis. Br J Dermatol 1992; 126: 535-41. [CrossRef] 
11. Fatahzadeh M. Kaposi sarcoma rewiew and medical management update. Oral Surg Oral Med Oral Pathol Oral Radiol 2012; 113 : 2-16. [CrossRef]
12. Sgadari C, Toschi E, Palladino C, Barillari G, Carlei D, Cereseto A, et al. Mechanism of paclitaxel activity in Kaposi's sarcoma. J Immunol 2000; 165: 509-17. [CrossRef] 